\title{
Effect of curcumin supplement or placebo in delayed onset muscle soreness: a systematic review and meta-analysis
}

\author{
Natthanichar Rattanaseth ${ }^{1}$, Patteera Panyarapeepat ${ }^{1}$, Janisa Andrea Muljadi ${ }^{2}$, Kornkit Chaijenkij ${ }^{3}$ and \\ Jatupon Kongtharvonskul ${ }^{4,5 *}$
}

\begin{abstract}
Background: There are multiple strategies that have been suggested to attenuate delayed onset muscle soreness (DOMS). Curcumin has been shown to reduce exercise-induced oxidative stress (OS) and inflammation. However, currently, there is still controversy.

Main body of the abstract: We conduct this meta-analysis according to the PRISMA guidelines. Relevant studies were included from Medline and Scopus from the date of inception to May 04th, 2021 that reported VAS score, blood markers (creatinine kinese (CK), tumor necrotic factor (TNF)- $\alpha$ and interleukin (IL)-6) and range of motion of either group. There were total of 13 studies including 202 and 176 persons in curcumin and placebo group. The unstandardized mean difference (UMD) of VAS muscle soreness in post-exercise, 1, 2, 3 and 4 days was - 0.12 (95\% $\mathrm{Cl}-0.46,0.22),-0.38(-0.83,0.08),-0.67(-1.19,-0.16),-0.86(-1.38,-0.34),-0.81(-1.27,-036)$ and -1.24 $(-1.50,-0.99)$ scores lower in curcumin when compared to placebo. The UMD of CK was $-11.07(95 \% \mathrm{Cl}-24$, $1.86),-37.51(-68.04,-6.97),-45.40(-95.67,4.86),-53.33(-128.11,21.45),-90.98(-173.45,-8.51)$ and 117.84 $(-338.69,574.37)$ lower in curcumin when compared to placebo. No statistically significantly differences were noted for IL-6, TNF-a and ROM between two groups.
\end{abstract}

Short conclusion: This meta-analysis suggested that curcumin supplement reduced delayed onset muscle soreness and CK after exercise in 1, 2, 3, and 4 days when compared to placebo. However, TNF and IL were not affected by curcumin ingestion.

Level of evidencel.

Keywords: DOMS, Curcumin, Exercise-induced muscle soreness, Meta-analysis

\section{Background}

Delayed onset muscle soreness (DOMS) normally occurs approximately 1 to 2 days after the unaccustomed activity and eccentric muscle contraction, with a symptom of muscle soreness and discomfort (Kim and So 2019; Mizumura and Taguchi 2016; Lewis et al. 2012).

\footnotetext{
*Correspondence: Jatupon_kong@hotmail.com

${ }^{4}$ Department of Epidemiology and Biostatistics, Faculty of Medicine Ramathibodi Hospital, Bangkok, Thailand

Full list of author information is available at the end of the article
}

Normally, DOMS is one symptom of exercise-induced muscle damage (EIMD) (Howatson and Someren 2008). Researchers have proposed several hypotheses for the etiology of DOMS previously such as lactic acid, muscle spasms, muscle damage, and inflammatory response, whereas novel hypotheses include Toll-like receptor 4 activation, increased levels of neurotrophic factors such as nerve growth factors and glial cell line-derived neurotrophic factors; however, the exact cause of DOMS remains unclear (Urai et al. 2013; Ota et al. 2013; Cheung et al. 2003; Smith 1991; Yoon et al. 2020). Delayed onset 


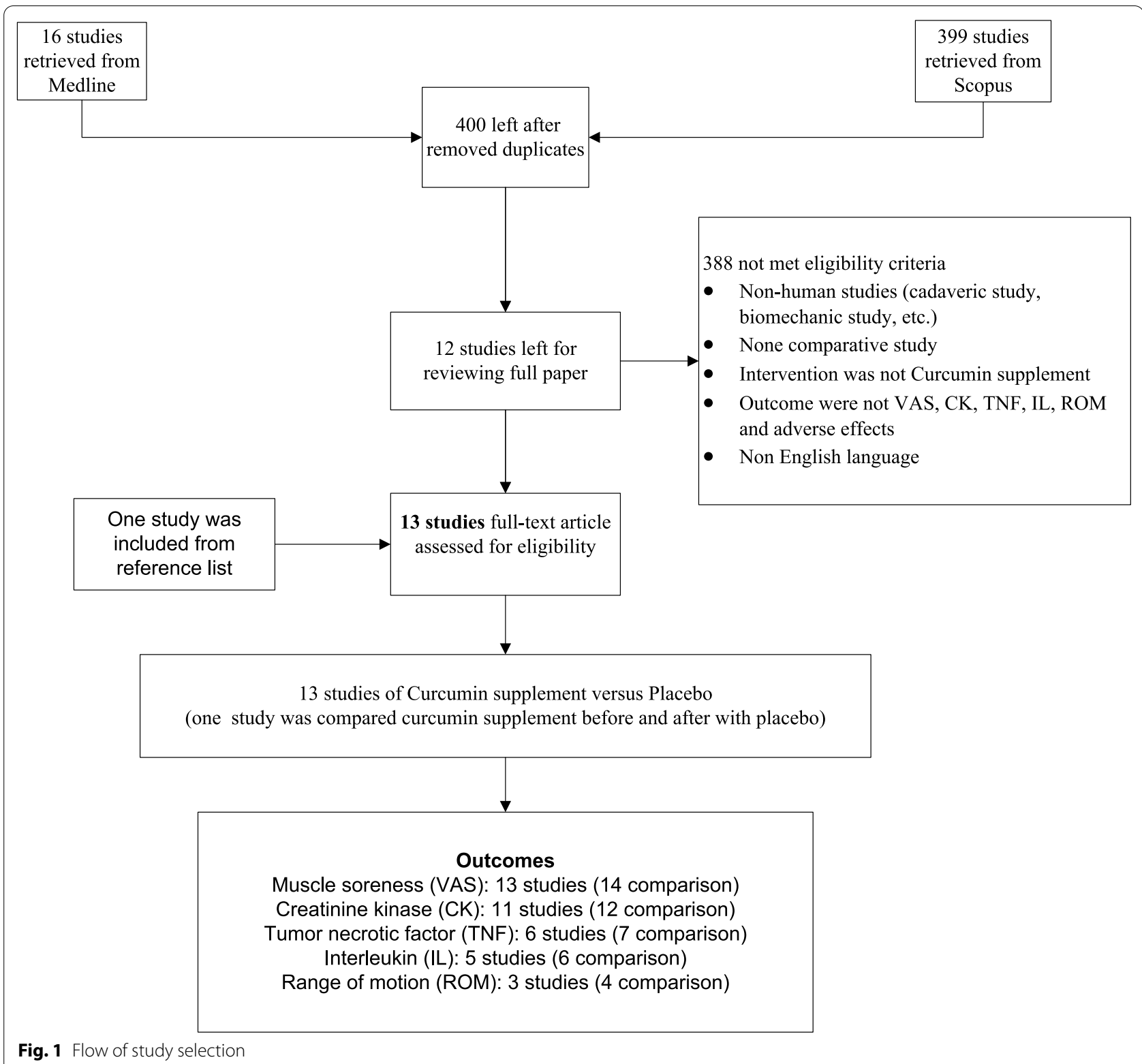

muscle soreness (DOMS) is a combination of muscle pain and stiffness occurring several hours after unaccustomed exercise, particularly when eccentric muscle activity is involved, it can induce muscle damage (Tanabe et al. 2019; Clarkson et al. 1992). An inflammatory response and the reactive oxygen species (ROS) production were triggered by this mechanical stress. The reason behind this process is that the mechanical stress promotes the activation of transcription factors such as nuclear factor- $\mathrm{kB}(\mathrm{NF}-\mathrm{\kappa B})$, and it would result in limiting an athlete's performance and daily activities (GarcíaLópez et al. 2007). EIMD can be manifested by prolonged decline in muscle strength, reduction in range of motion
(ROM), swelling, DOMS and an increase in blood muscle proteins, including creatine kinase (CK) activity (Clarkson et al. 1992; García-López et al. 2007; Tiidus 1998; Warren et al. 1999; Takahashi et al. 1994). Muscle function impairment caused by damaged and its subsequent inflammatory responses may reduce the ability to perform daily training and reduce athletic performance. Therefore, post-exercise muscle damage should be prevented or minimized (Tanabe et al. 2019). At present, multiple strategies have been treated to attenuate DOMS such as hyperbaric oxygen, anti-inflammatory medication, massage, cryotherapy, homeopathy, stretching, electrotherapeutic modalities, ultrasound, rest, and light 


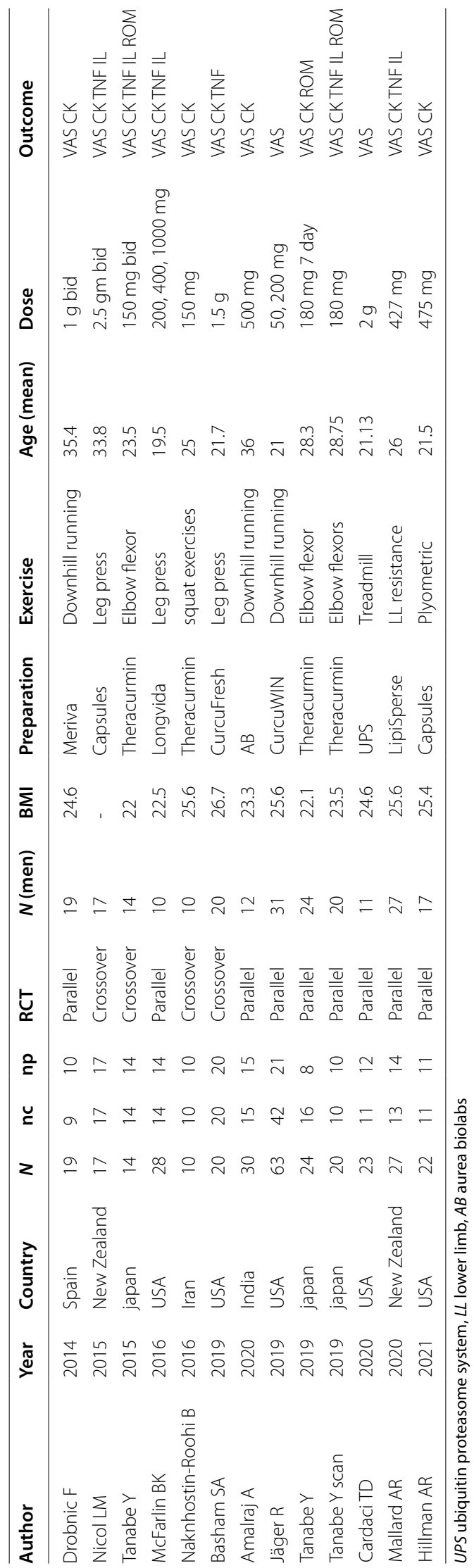


Table 2 Risk of bias assessment

\begin{tabular}{|c|c|c|c|c|c|}
\hline Author & Sequence generation & Allocation concealment & Blinding & $\begin{array}{l}\text { Incomplete outcome } \\
\text { data }\end{array}$ & $\begin{array}{l}\text { Selective } \\
\text { outcome } \\
\text { report }\end{array}$ \\
\hline Drobnic F & Y & Y & Y & Y & Y \\
\hline Nicol LM & Y & Y & N & Y & Y \\
\hline Tanabe Y & U & $\mathrm{N}$ & $\mathrm{N}$ & Y & Y \\
\hline McFarlin BK & Y & Y & Y & Y & Y \\
\hline Naknhostin-Roohi B & U & N & Y & Y & Y \\
\hline Basham SA & U & $\mathrm{N}$ & Y & Y & Y \\
\hline Amalraj A & Y & Y & Y & Y & Y \\
\hline Jäger $R$ & Y & Y & Y & Y & Y \\
\hline Tanabe Y & U & $\mathrm{N}$ & $\mathrm{N}$ & Y & Y \\
\hline Tanabe Y scan & U & $\mathrm{N}$ & $\mathrm{N}$ & Y & Y \\
\hline Cardaci TD & Y & Y & Y & Y & Y \\
\hline Mallard AR & Y & Y & Y & Y & Y \\
\hline Hillman AR & Y & Y & Y & Y & $Y$ \\
\hline
\end{tabular}

exercise. Nutritional interventions with antioxidant and anti-inflammatory properties are frequently reported to reduce DOMS.

Curcumin is a natural polyphenolic substance extracted from turmeric. It has various physiological effects, such as membrane protective effects, as well as anti-inflammatory and antioxidant responses (Thapa et al. 2013; Hatcher et al. 2008). These mechanisms have been reported to suppress the activity of NF- $\mathrm{B}$, thereby suppressing the expression of IL-6 and tumor necrotic factor TNF- $\alpha$ (Cho et al. 2007; Aggarwal et al. 2006), which is a modulating factor for cytokines and cyclooxygenase (COX) (Thapa et al. 2013; Hatcher et al. 2008; Cho et al. 2007; Aggarwal et al. 2006; Chun et al. 2003). Therefore, these actions are considered to have a positive effect on DOMS. However, outcomes (muscle soreness, CK, TNF- $\alpha$, IL- 6 and ROM) of the curcumin and placebo are inconsistent. Some studies show benefit with intake of curcumin supplement (Tanabe et al. 2019, 2015; Hillman et al. 2021), while other studies do not (Nicol et al. 2015; McFarlin et al. 2016; Drobnic et al. 2014; Mallard and Briskey 2020; Jäger et al. 2019; Ms et al. 2020). A previous meta-analysis (Fang and Nasir 2021) found that the efficacy of curcumin in reducing CK serum levels and muscle soreness index among adults, however, it included a study that combined curcumin and piperine supplement and compared to placebo, which should be excluded. Moreover, the previous meta-analyses did not assess other relevant outcomes (TNF- $\alpha$, IL-6 and ROM), importance sources of heterogeneity (e.g., preoperative exercise, age, and dosage of curcumin supplement) with subgroup analysis and publication biases were not assessed. Furthermore, some of the other randomized controlled trial studies (RCTs) (Hillman et al. 2021; Mallard and Briskey 2020; Amalraj et al. 2020; Cardaci et al. 2020) that have since been published were not included. Therefore, this meta-analysis of curcumin supplement versus placebo was conducted. This study aims to update the comparisons between curcumin supplement and placebo of muscle soreness and CK and adds comparisons of TNF- $\alpha$, IL- 6 and ROM.

\section{Main text}

Search strategy and data sources

This review was conducted according to the transparent reporting of systematic reviews and meta-analyses (PRISMA guideline 2009). The search was performed in two databases: PubMed and Scopus; from the date of inception to May $04^{\text {th }}, 2021$. The keywords were used as following search terms: ((Delayed onset muscle soreness) OR (DOMS)) AND (curcumin)). Manual search for reference lists of all included studies was screened for further eligible articles identification. The studies were screened independently by two authors (J.M. and P.K.) against the eligibility criteria based on titles and abstracts using bibliographical software package, EndNote version X7. Disagreements were resolved regarding inclusion and exclusion criteria of a study with a third author (J.K.)

\section{Inclusion criteria}

Studies were included if they met the following criteria: (a) RCT and quasi-RCT studies; (b) studies that reported outcomes as following: muscle soreness index (VAS), creatinine kinase (CK); tumor necrotic factor-alpha (TNF$\alpha$ ), interleukin-6 (IL-6) and range of motion (ROM); (c) studies that compared clinical outcomes between 
Table 3 Comparisons of VAS between curcumin supplement and placebo

\begin{tabular}{|c|c|c|c|c|c|c|}
\hline \multirow[t]{2}{*}{ Author } & \multicolumn{3}{|c|}{ Curcumin } & \multicolumn{3}{|c|}{ Placebo } \\
\hline & $N$ & Mean & SD & $N$ & Mean & SD \\
\hline \multicolumn{7}{|l|}{ (a) VAS preexercise } \\
\hline Nicol LM & 17 & 0 & 0 & 17 & 0 & 0 \\
\hline Tanabe Y & 14 & 0.68 & 0.91 & 14 & 0.34 & 0.57 \\
\hline McFarlin BK & 14 & 0.16 & 0.53 & 14 & 0.21 & 0.63 \\
\hline Naknhostin-Roohi B & 10 & 5.93 & 0.19 & 10 & 5.93 & 0.37 \\
\hline Basham SA & 20 & 3.089 & 0.206 & 20 & 3.795 & 0.206 \\
\hline Amalraj A (VAS 0-4) & 15 & 2.91 & 0.36 & 15 & 2.65 & 0.459 \\
\hline Jäger R (200 mg) & 21 & 0 & 0 & 21 & 0 & 0 \\
\hline Tanabe Y (pre) & 8 & 0.833 & 0.625 & 8 & 1.04 & 0.94 \\
\hline Tanabe Y (post) & 8 & 1.04 & 1.25 & 8 & - & - \\
\hline Tanabe Y scan (0-10) pre & 10 & 0.676 & 0.795 & 10 & 0.636 & 0.477 \\
\hline Tanabe Y scan (0-10) post & 10 & 0.954 & 1.113 & 10 & 1.193 & 1.113 \\
\hline Mallard AR (0-10) & 13 & 0.375 & 0.625 & 14 & 0.375 & 0.5 \\
\hline Hillman AR & 11 & 0.149 & 0.223 & 11 & 1.334 & 2.074 \\
\hline UMD (95\% Cl) & & & & -0 & & \\
\hline \multicolumn{7}{|l|}{ (b) VAS post-exercise } \\
\hline Nicol LM & 17 & 2 & 1.5 & 17 & 1.75 & 1.75 \\
\hline Tanabe Y & 14 & 1.36 & 1.48 & 14 & 1.42 & 1.59 \\
\hline Jäger R (50 mg) & - & 2.97 & 1.73 & 21 & - & - \\
\hline Jäger R (200 mg) & 21 & 2.14 & 0.99 & 21 & 2.97 & 1.81 \\
\hline Tanabe Y (pre) & 8 & 1.04 & 0.833 & 8 & 1.56 & 1.87 \\
\hline Tanabe Y (post) & 8 & 1.46 & 1.88 & 8 & - & - \\
\hline Tanabe Y scan (0-10) pre & 10 & 0.795 & 0.795 & 10 & 1.113 & 2.385 \\
\hline Tanabe Y scan (0-10) post & 10 & 1.431 & 1.67 & 10 & 1.749 & 1.749 \\
\hline Mallard AR (0-10) & 13 & 3 & 2.5 & 14 & 2.5 & 2.25 \\
\hline Hillman AR & 11 & 0.963 & 1.334 & 11 & 2.963 & 2.963 \\
\hline UMD (95\%Cl) & & & & -0 & & \\
\hline \multicolumn{7}{|l|}{ (c) VAS at $24 \mathrm{~h}$} \\
\hline Nicol LM & 17 & 2.87 & 1.33 & 17 & 3 & 2 \\
\hline Tanabe Y & 14 & 4.32 & 2.5 & 14 & 4.77 & 1.82 \\
\hline McFarlin BK & 14 & 3.53 & 0.32 & 14 & 4.84 & 0.63 \\
\hline Naknhostin-Roohi B & 10 & 6.48 & 0.09 & 10 & 6.85 & 0.19 \\
\hline Jäger R (50 mg) & - & 5.36 & 1.81 & 21 & - & - \\
\hline Jäger R (200 mg) & 21 & 3.63 & 0.99 & 21 & 5.53 & 1.65 \\
\hline Tanabe Y (pre) & 8 & 4.375 & 1.458 & 8 & 4.69 & 2.29 \\
\hline Tanabe Y (post) & 8 & 3.44 & 1.46 & 8 & - & - \\
\hline Tanabe Y scan (0-10) pre & 10 & 3.975 & 1.272 & 10 & 3.657 & 1.272 \\
\hline Tanabe Y scan (0-10) post & 10 & 4.216 & 1.91 & 10 & 3.897 & 1.67 \\
\hline Mallard AR (0-10) & 13 & 1.625 & 1.813 & 14 & 2.188 & 1.875 \\
\hline Hillman AR & 11 & 2.667 & 1.778 & 11 & 4.667 & 3.482 \\
\hline UMD (95\%Cl) & & & & -0 & & \\
\hline \multicolumn{7}{|l|}{ (d) VAS at $48 \mathrm{~h}$} \\
\hline Drobnic F & 9 & 2.33 & 0.79 & 10 & 3.06 & 7.9 \\
\hline Nicol LM & 17 & 2.2 & 1.33 & 17 & 3.2 & 2.2 \\
\hline Tanabe Y & 14 & 5.45 & 2.05 & 14 & 5.97 & 2.27 \\
\hline McFarlin BK & 14 & 5.26 & 0.42 & 14 & 6.95 & 0.63 \\
\hline Naknhostin-Roohi B & 10 & 6.67 & 0.19 & 10 & 8.33 & 0.19 \\
\hline Jäger R (50 mg) & - & 4.289 & 1.98 & 21 & - & - \\
\hline
\end{tabular}


Table 3 (continued)

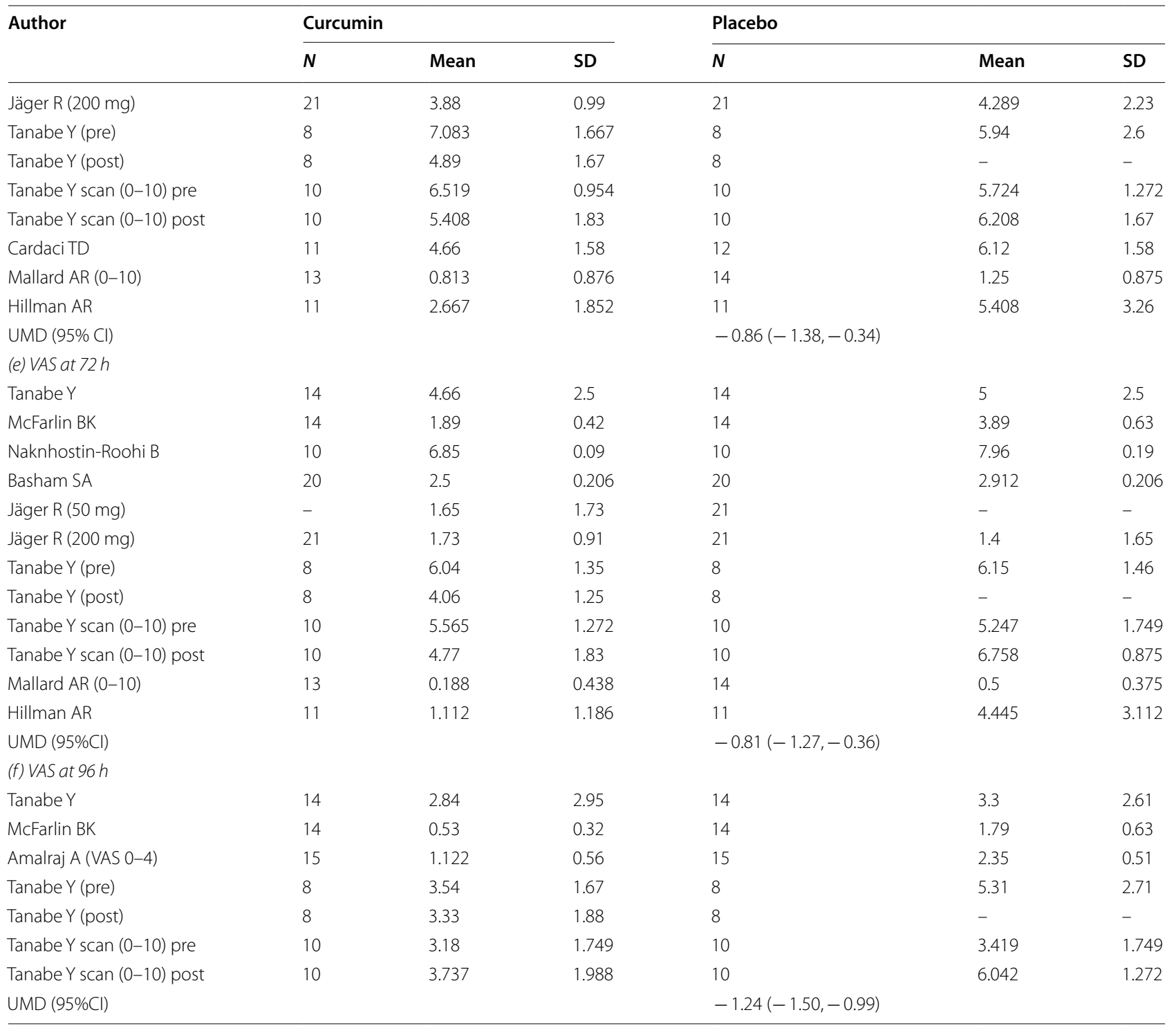

curcumin supplement and placebo; (d) There had adequate data for extracted and pooled. We excluded studies if they were using a combination of intervention besides curcumin supplement, experimental and animal studies, reviews, letters to editor, or case reports and non-English languages studies.

\section{Data extraction and methodology quality assessment}

The data were extracted from each study through structured data extraction forms by two reviewers (N.R. and P.P.), using data extraction forms. The items extracted were baseline characteristics of the study that included average age, sex, study design, mean follow-up time and dose of curcumin. Clinical outcomes data number of subjects, means, and SD of VAS and CK) between groups were extracted and followed by data extraction of frequencies (adverse effect) between treatment groups. In case of any disagreements in opinion, a third author (J.M.) decision would be required. Quality assessment was performed by two authors (N.R. and P.P.) according to the Cochrane Collaboration tool for evaluating the risk of bias in order to avoid the distortion of the metaanalysis outcomes (Liberati et al. 2009). RCT studies were assessed by risk of bias followed by the PRISMA guideline recommendation based on sequence generation, allocation concealment, blinding, incomplete outcome data, selective outcome reporting, and other sources of 


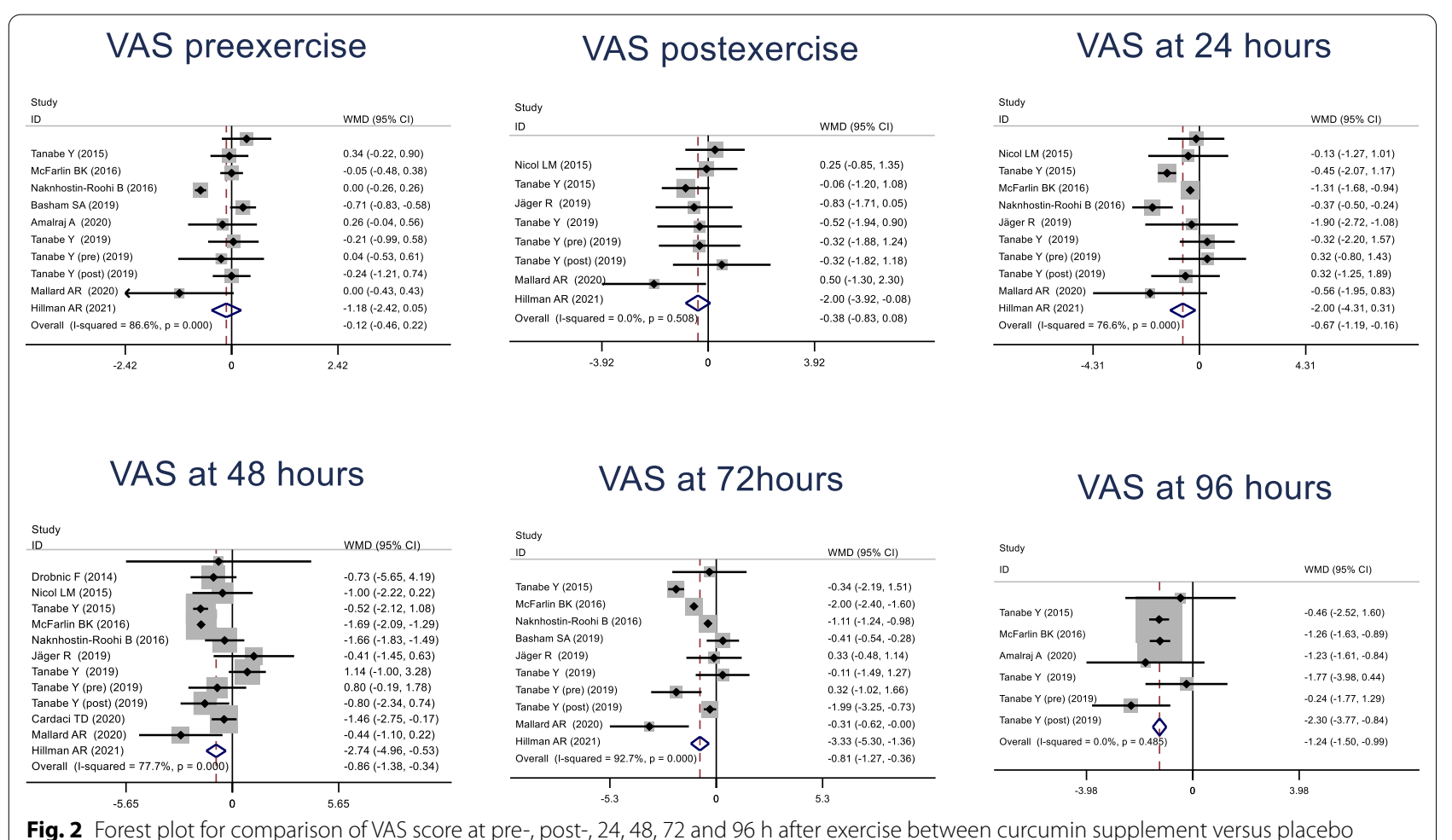

Fig. 2 Forest plot for comparison of VAS score at pre-, post-, 24, 48, 72 and $96 \mathrm{~h}$ after exercise between curcumin supplement versus placebo

bias. Any conflicts between reviewers for quality assessment were settled by third reviewer (J.K.).

\section{Outcomes of interest}

The outcomes were VAS of muscle soreness, CK, TNF- $\alpha$, IL- 6 and ROM. The measurement of those outcomes was the same as reported in the original studies, which were VAS of muscle soreness (0-10); lower values are equivalent to better outcomes. For CK, TNF- $\alpha$, IL- 6 , lower values are equivalent to better outcomes. For ROM, higher values are equivalent to better outcomes.

\section{Statistical methods}

For continuous data, data were pooled as unstandardized mean difference (UMD) with 95\% confidence interval (CI). The heterogeneity across the studies was assessed using $Q$ statistic and I2 statistic for quantifying the degree of heterogeneity. $I^{2}$ value equal to $0 \%$ is considered as no, $25 \%$ as low, $50 \%$ as moderate and $75 \%$ as high heterogeneity. The statistical significance for heterogeneity was set with a $P$ value $<0.10$. A random-effect model was used if $I^{2}>25$, otherwise a fixed effects model was applied. In order to explore the cause of heterogeneity, meta-regression was applied in the meta-regression model. According to the results of meta-regression, sensitivity analyses were performed by leave-one-out to assess the robustness of a pooled conclusion. The funnel plots and Egger test were used to assess the publication bias (Palmer et al. 2020; Egger et al. 1997). The metatrim and fill method was used to estimate the number of studies that might be missing and to adjust the pooled estimate (Duval and Tweedie 2000). Data were analyzed using STATA version 15.0 (StataCorp. 2017). $P$ value $<0.05$ was considered statistically significant. $P$ value of $<0.10$ was considered as a threshold of significant heterogeneity.

\section{Results}

We identified 16 and 399 studies from Medline and Scopus, respectively (Fig. 1); 15 studies were duplicated, leaving 400 studies to review titles and abstracts. Of these, 12 full papers and a study, which was identified from the reference list, were reviewed and leaving a total of 13 studies for data extraction. Characteristics of the 13 studies (Tanabe et al. 2019, 2015; Hillman et al. 2021; Nicol et al. 2015; McFarlin et al. 2016; Drobnic et al. 2014; Mallard and Briskey 2020; Jäger et al. 2019; Ms et al. 2020; Amalraj et al. 2020; Cardaci et al. 2020; Nakhostin-Roohi et al. 2016) are described in Table 1. All studies were RCTs. Nine studies were parallel design, while four studies were crossover design. All 13 studies (Tanabe et al. 2019, 2015; Hillman et al. 2021; Nicol et al. 2015; McFarlin et al. 2016; Mallard and Briskey 2020; Jäger et al. 2019; Ms et al. 2020; Amalraj et al. 2020; Cardaci et al. 2020; NakhostinRoohi et al. 2016) were reported of post-exercise muscle 
Table 4 Comparisons of CK between curcumin supplement and placebo

\begin{tabular}{|c|c|c|c|c|c|c|}
\hline \multirow[t]{2}{*}{ Author } & \multicolumn{3}{|c|}{ Curcumin } & \multicolumn{3}{|l|}{ Placebo } \\
\hline & $N$ & Mean & SD & $N$ & Mean & SD \\
\hline \multicolumn{7}{|l|}{ (a) CK preexercise } \\
\hline Drobnic F & 9 & 193 & 64.18 & 10 & 236 & 64.18 \\
\hline McFarlin BK & 14 & 88.61 & 50.63 & 14 & 94.94 & 50.63 \\
\hline Naknhostin-Roohi B & 10 & 36.49 & 6.76 & 10 & 45.95 & 4.05 \\
\hline Basham SA & 20 & 214.7 & 14.7 & 20 & 235.295 & 23.53 \\
\hline Amalraj A & 15 & 129.79 & 93.06 & 15 & 112.65 & 39.18 \\
\hline Mallard AR (0-10) & 13 & 278.6 & 144.3 & 14 & 180.4 & 90.6 \\
\hline Hillman AR & 11 & 230.77 & 288.47 & 11 & 326.93 & 336.54 \\
\hline UMD (95\% Cl) & & & & $\begin{array}{l}-11.07(-24.00,1.86) \\
-11.07(-24.00,1.86)\end{array}$ & & \\
\hline \multicolumn{7}{|l|}{ (b) CKpost-exercise } \\
\hline Drobnic F & 9 & 250 & 9.3 & 10 & 264 & 9.3 \\
\hline Nicol LM & 17 & 100 & 300 & 17 & 200 & 320 \\
\hline McFarlin BK & 14 & 234.18 & 44.3 & 14 & 373.42 & 50.63 \\
\hline Naknhostin-Roohi B & 10 & 67.57 & 10.82 & 10 & 83.78 & 5.405 \\
\hline Mallard AR (0-10) & 13 & 329.1 & 147.8 & 14 & 231.6 & 107.2 \\
\hline Hillman AR & 11 & 326.93 & 307.71 & 11 & 365.39 & 384.62 \\
\hline UMD (95\%Cl) & & & & $-37.51(-68.04,-6.97)$ & & \\
\hline \multicolumn{7}{|l|}{ (c) CKat $24 \mathrm{~h}$} \\
\hline Drobnic F & 9 & 579 & 76.4 & 10 & 693 & 76.4 \\
\hline Nicol LM & 17 & 100 & 300 & 17 & 200 & 320 \\
\hline Tanabe Y & 14 & 23.809 & 95.238 & 14 & 47.619 & 95.238 \\
\hline McFarlin BK & 14 & 151.9 & 50.63 & 14 & 272.15 & 50.63 \\
\hline Naknhostin-Roohi B & 10 & 68.92 & 10.82 & 10 & 109.46 & 10.82 \\
\hline Tanabe Y & 8 & 344 & 647 & 8 & 0 & 0 \\
\hline Tanabe Y (pre) & 10 & 260.87 & 608.696 & 10 & 173.913 & 478.261 \\
\hline Tanabe Y (post) & 10 & 130.435 & 217.391 & 10 & 43.478 & 130.435 \\
\hline Mallard AR (0-10) & 13 & 380.3 & 166.1 & 14 & 260.8 & 99.9 \\
\hline Hillman AR & 11 & 255.77 & 326.93 & 11 & 500 & 336.54 \\
\hline UMD (95\%Cl) & & & & $-45.40(-95.67,4.86)$ & & \\
\hline \multicolumn{7}{|l|}{ (d) CKat $48 \mathrm{~h}$} \\
\hline Nicol LM & 17 & 50 & 220 & 17 & 90 & 200 \\
\hline Tanabe Y & 14 & 47.619 & 59.524 & 14 & 190.476 & 333.333 \\
\hline McFarlin BK & 14 & 139.24 & 50.63 & 14 & 291.14 & 50.63 \\
\hline Naknhostin-Roohi B & 10 & 75.68 & 10.82 & 10 & 116.22 & 16.21 \\
\hline Tanabe Y & 8 & 1164 & 1810 & 8 & 129 & 129 \\
\hline Tanabe Y (pre) & 10 & 1000 & 1652.174 & 10 & 434.783 & 826.087 \\
\hline Tanabe Y (post) & 10 & 304.348 & 173.913 & 10 & 217.391 & 347.826 \\
\hline Mallard AR (0-10) & 13 & 348.5 & 249.4 & 14 & 225.5 & 88 \\
\hline Hillman AR & 11 & 211.54 & 134.62 & 11 & 403.85 & 326.94 \\
\hline UMD (95\%Cl) & & & & $-53.33(-128.11,21.45)$ & & \\
\hline \multicolumn{7}{|l|}{ (e) $C K$ at $72 \mathrm{~h}$} \\
\hline Tanabe Y & 14 & 452.38 & 214.286 & 14 & 833.333 & 761.905 \\
\hline McFarlin BK & 14 & 145.57 & 50.63 & 14 & 405.06 & 50.63 \\
\hline Naknhostin-Roohi B & 10 & 78.38 & 10.82 & 10 & 102.7 & 10.82 \\
\hline Basham SA & 20 & 200 & 35.29 & 20 & 294.118 & 29.412 \\
\hline Tanabe Y & 8 & 1681 & 2069 & 8 & 733 & 776 \\
\hline Tanabe Y (pre) & 10 & 1608.696 & 1913.043 & 10 & 1000 & 1391.304 \\
\hline
\end{tabular}


Table 4 (continued)

\begin{tabular}{|c|c|c|c|c|c|c|}
\hline \multirow[t]{2}{*}{ Author } & \multicolumn{3}{|c|}{ Curcumin } & \multicolumn{3}{|l|}{ Placebo } \\
\hline & $N$ & Mean & SD & $N$ & Mean & SD \\
\hline Tanabe Y (post) & 10 & 826.087 & 1086.957 & 10 & 1043.478 & 1304.348 \\
\hline Mallard AR (0-10) & 13 & 285.4 & 125 & 14 & 211 & 138.3 \\
\hline Hillman AR & 11 & 192.31 & 115.39 & 11 & 288.47 & 182.7 \\
\hline UMD (95\%Cl) & & & & $\begin{array}{l}-90.98(-173.45,-8.51) \\
-90.98(-173.45,-8.51)\end{array}$ & & \\
\hline \multicolumn{7}{|l|}{ (f) CKat $96 \mathrm{~h}$} \\
\hline Tanabe Y & 14 & 309.524 & 333.333 & 14 & 761.905 & 8571.43 \\
\hline Amalraj A & 15 & 107.76 & 41.63 & 15 & 124.89 & 31.84 \\
\hline Tanabe Y & 8 & 2026 & 1724 & 8 & 1250 & 1164 \\
\hline Tanabe Y (pre) & 10 & 1869.565 & 169.552 & 10 & 1173.913 & 1086.957 \\
\hline Tanabe Y (post) & 10 & 1086.957 & 1173.913 & 10 & 1739.13 & 1043.478 \\
\hline UMD (95\%Cl) & & & & $117.84(-338.69,574.37)$ & & \\
\hline
\end{tabular}

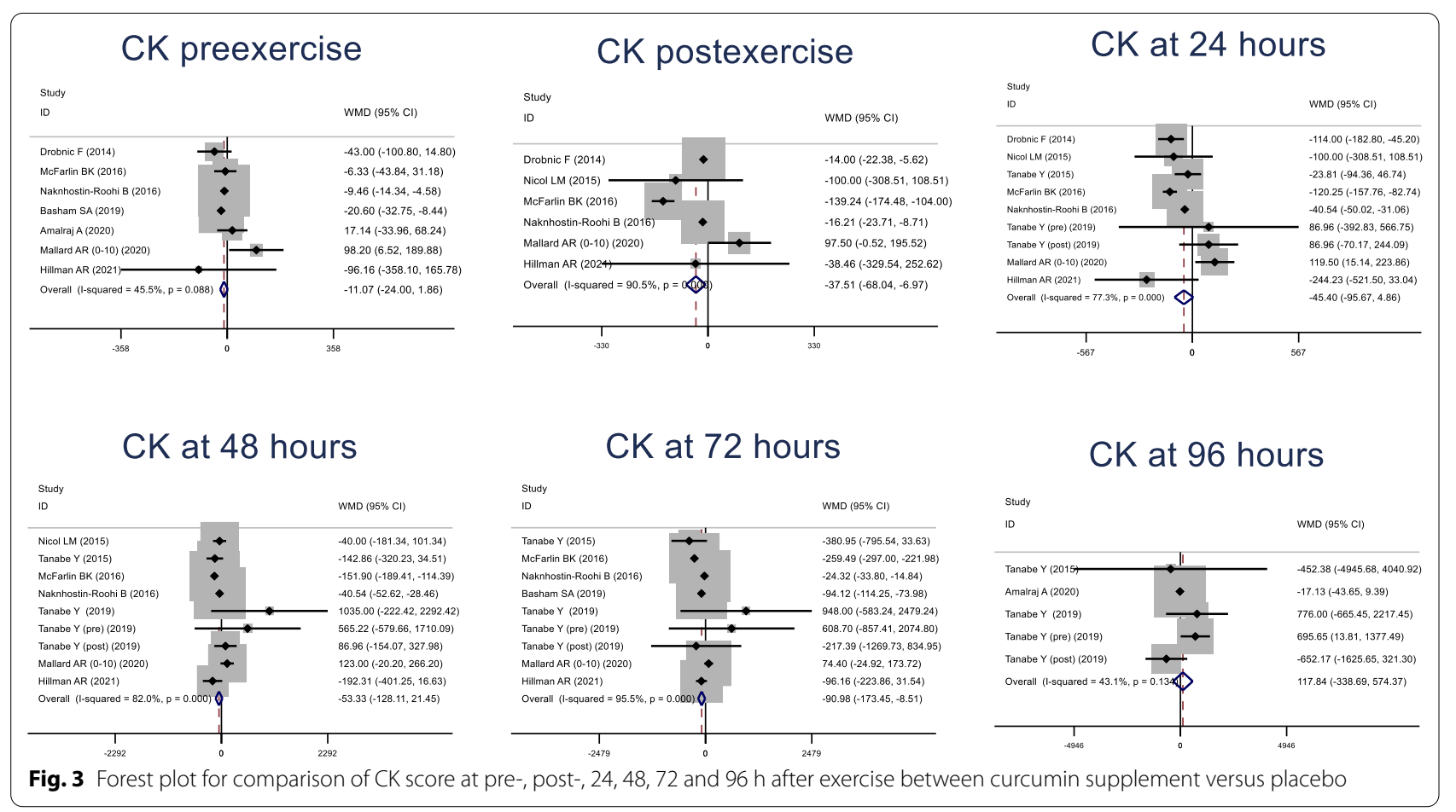

soreness using VAS. Indirect markers of muscle damage were reported using CK in 11 studies (Tanabe et al. 2019, 2015; Hillman et al. 2021; Nicol et al. 2015; McFarlin et al. 2016; Drobnic et al. 2014; Mallard and Briskey 2020; Ms et al. 2020; Amalraj et al. 2020; Nakhostin-Roohi et al. 2016), TNF- $\alpha$ in six studies (Tanabe et al. 2019, 2015; Nicol et al. 2015; McFarlin et al. 2016; Mallard and Briskey 2020; Ms et al. 2020) and IL-6 in five studies (Tanabe et al. 2019, 2015; Nicol et al. 2015; McFarlin et al. 2016; Mallard and Briskey 2020). Post-exercise ROM was reported in three studies (Tanabe et al. 2019, 2015). Mean age and BMI of participants varied from 19.5 to 36 years and 22 to 26.2, respectively. Eight studies reported percentages of male gender 100 percent. While four studies reported percentages of male gender from 36 to 77 percent. Eight studies were active exercise, while five studies were resistive exercise.

\section{Risk of bias in included studies}

Risk of bias is described in Table 2. Among 13 studies, no selective outcome reporting and incomplete outcome 
Table 5 Comparisons of TNF between curcumin supplement and placebo

\begin{tabular}{|c|c|c|c|c|c|c|}
\hline \multirow[t]{2}{*}{ Author } & \multicolumn{3}{|c|}{ Curcumin } & \multicolumn{3}{|c|}{ Placebo } \\
\hline & $N$ & Mean & SD & $N$ & Mean & SD \\
\hline \multicolumn{7}{|c|}{ (a) TNF preexercise } \\
\hline Nicol LM & 17 & -0.5 & 0 & 17 & -0.5 & 0 \\
\hline Tanabe Y & 14 & 1.83 & 0.7 & 14 & 1.62 & 0.28 \\
\hline McFarlin BK & 14 & 3.73 & 0.22 & 14 & 3.87 & 0.37 \\
\hline Basham SA & 20 & 1.17 & 0.1 & 20 & 1.12 & 0.04 \\
\hline Tanabe Y (pre) & 10 & 0.63 & 0.18 & 10 & 0.63 & 0.17 \\
\hline Tanabe Y (post) & 10 & 0.59 & 0.16 & 10 & 0.58 & 0.18 \\
\hline Mallard AR & 13 & 8 & 5.5 & 14 & 5.5 & 3.7 \\
\hline UMD (95\% Cl) & & & & 0.0 & & \\
\hline \multicolumn{7}{|c|}{ (b) TNF post-exercise } \\
\hline Nicol LM & 17 & 2.5 & 2.5 & 17 & 2.8 & 8 \\
\hline Tanabe Y & 14 & 1.55 & 0.42 & 14 & 1.97 & 1.55 \\
\hline Basham SA & 20 & 1.14 & 0.1 & 20 & 1.09 & 0.04 \\
\hline Tanabe Y (pre) & 10 & 0.61 & 0.19 & 10 & 0.61 & 0.19 \\
\hline Tanabe Y (post) & 10 & 0.59 & 0.11 & 10 & 0.62 & 0.09 \\
\hline Mallard AR & 13 & 7.5 & 3.4 & 14 & 3.4 & 3.1 \\
\hline UMD (95\%Cl) & & & & 0.0 & & \\
\hline \multicolumn{7}{|l|}{ (c) TNF at $24 \mathrm{~h}$} \\
\hline Nicol LM & 17 & 1.5 & 1.4 & 17 & 2 & 4 \\
\hline Tanabe Y & 14 & 1.62 & 0.35 & 14 & 1.83 & 0.35 \\
\hline McFarlin BK & 14 & 3.58 & 0.22 & 14 & 4.75 & 0.37 \\
\hline Basham SA & 20 & 0.1 & 0.1 & 20 & 0.96 & 0.04 \\
\hline Tanabe Y (pre) & 10 & 0.58 & 0.19 & 10 & 0.56 & 0.14 \\
\hline Tanabe Y (post) & 10 & 0.16 & 0.54 & 10 & 0.55 & 0.17 \\
\hline Mallard AR & 13 & 8.4 & 4.1 & 14 & 4.1 & 2.6 \\
\hline UMD (95\%Cl) & & & & & & \\
\hline \multicolumn{7}{|l|}{ (d) TNF at $48 \mathrm{~h}$} \\
\hline Nicol LM & 17 & 3.5 & 0.5 & 17 & 0.8 & 2.66 \\
\hline Tanabe Y & 14 & 2.04 & 0.77 & 14 & 2.18 & 1.48 \\
\hline McFarlin BK & 14 & 3.73 & 0.22 & 14 & 4.75 & 0.37 \\
\hline Basham SA & 20 & 1.08 & 0.1 & 20 & 1.07 & 0.07 \\
\hline Mallard AR & 13 & 7.2 & 3.5 & 14 & 3.5 & 1.9 \\
\hline UMD (95\%Cl) & & & & & & \\
\hline \multicolumn{7}{|l|}{ (e) TNF at $72 \mathrm{~h}$} \\
\hline Tanabe Y & 14 & 1.83 & 0.28 & 14 & 1.76 & 0.28 \\
\hline McFarlin BK & 14 & 3.73 & 0.22 & 14 & 4.6 & 0.37 \\
\hline Tanabe Y (pre) & 10 & 0.58 & 0.18 & 10 & 0.56 & 0.15 \\
\hline Tanabe Y (post) & 10 & 0.59 & 0.13 & 10 & 0.58 & 0.17 \\
\hline Mallard AR & 13 & 7.4 & 3.5 & 14 & 3.5 & 2.3 \\
\hline UMD (95\%Cl) & & & & & & \\
\hline \multicolumn{7}{|l|}{ (f) TNF at $96 \mathrm{~h}$} \\
\hline Tanabe Y & 14 & 1.83 & 0.28 & 14 & 1.83 & 0.28 \\
\hline McFarlin BK & 14 & 3.65 & 0.22 & 14 & 4.68 & 0.44 \\
\hline UMD (95\%Cl) & & & & & & \\
\hline
\end{tabular}


TNF preexercise

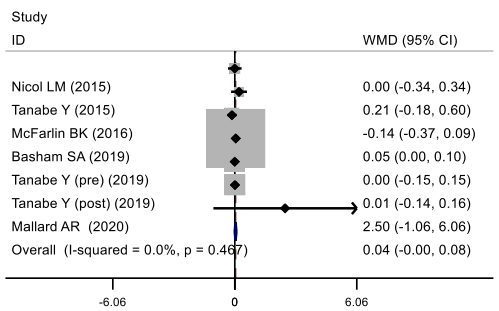

TNF at 48 hours

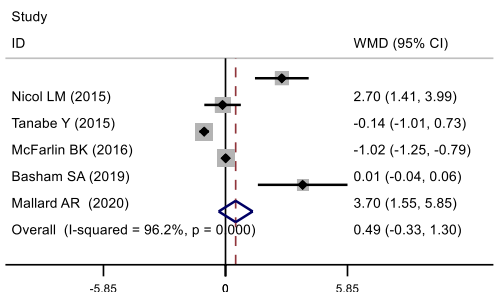

TNF postexercise

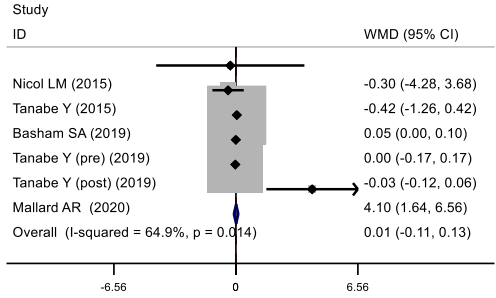

TNF at 72 hours

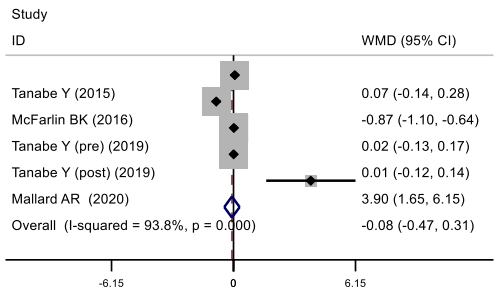

TNF at 24 hours

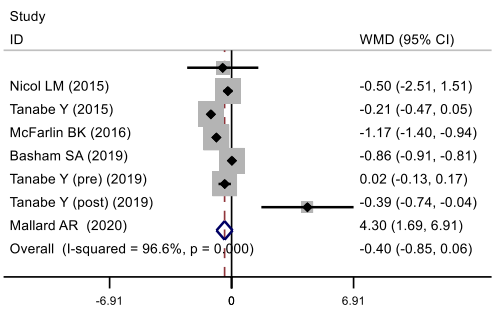

TNF at 96 hours

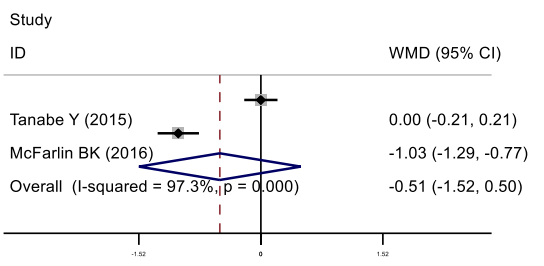

Fig. 4 Forest plot for comparison of TNF score at pre-, post-, 24, 48, 72 and $96 \mathrm{~h}$ after exercise between curcumin supplement versus placebo

report, followed by blinding (9/13), sequence generation $(8 / 13)$ and allocation concealment (8/13).

\section{Outcomes}

\section{VAS of muscle soreness at pre- and post-exercise, 24, 48, 72 and $96 h$}

The mean values of VAS of muscle soreness between curcumin and placebo in post-exercise person at pre- and post-exercise, 24, 48, 72 and $96 \mathrm{~h}$ are shown in Table 3 and Fig. 2. The pooled UMD was $-0.12(95 \% \mathrm{CI}-0.46$, $0.22),-0.38(-0.83,0.08),-0.67(-1.19,-0.16),-0.86$ $(-1.38,-0.34),-0.81 \quad(-1.27,-036) \quad$ and -1.24 $(-1.50,-0.99)$, i.e., mean VAS muscle soreness was approximately $-0.7,-0.9,-0.8$ and -1.2 score statistically significant difference between two groups at 24, 48, 72 and 96 h (Table 3; Fig. 2). Separately fitting preoperative exercise, age, sex, and body mass index and dosage of curcumin supplement at baseline in a meta-regression analysis and none of the co-variables could explain the heterogeneity. Egger's test and a contour funnel plot did not suggest any evidence of publication bias.

\section{CK at pre- and post-exercise, 24, 48, 72 and $96 \mathrm{~h}$}

The mean values of CK between curcumin and placebo in post-exercise person at pre- and post-exercise, 24, 48, 72 and $96 \mathrm{~h}$ are shown in Table 4 and Fig. 3. The UMD was -11.07 (95\% CI-24, 1.86), -37.51 $(-68.04,-6.97),-45.40 \quad(-95.67, \quad 4.86),-53.33$
$(-128.11,21.45),-90.98(-173.45,-8.51)$ and 117.84 $(-338.69,574.37) \mathrm{U} / \mathrm{L}$, i.e., mean CK was approximately -38 and $-91 \mathrm{U} / \mathrm{L}$ statistically significant difference between two groups at post-exercise and $72 \mathrm{~h}$ (Table 4; Fig. 3). None of the co-variables could explain the heterogeneity. Egger's test and a contour funnel plot did not suggest any evidence of publication bias.

\section{TNF- $\alpha$ at pre- and post-exercise, 24, 48, 72 and $96 h$}

The mean values of TNF- $\alpha$ between curcumin and placebo in post-exercise person at pre- and post-exercise, 24, 48, 72 and $96 \mathrm{~h}$ are shown in Table 5 and Fig. 4. The UMD was $-0.04(95 \% \mathrm{CI}-0.00,0.08), 0.01(-0.11$, $0.13),-0.40(-0.85,0.06), 0.49(-0.33,1.30),-0.08$ $(-0.47,0.31)$ and $-0.51(-1.52,0.50) \mathrm{pg} / \mathrm{mL}$, i.e., mean TNF- $\alpha$ was not significant difference between two groups at post any time point. Egger's test and a contour funnel plot did not suggest any evidence of publication bias.

\section{IL-6 at pre- and post-exercise, 24, 48, 72 and $96 \mathrm{~h}$}

The mean values of IL- 6 between curcumin and placebo in post-exercise person at preexercise, 24, 48, 72 and $96 \mathrm{~h}$ are shown in Table 6 and Fig. 5. UMD was $-0.03(95 \%$ $\mathrm{CI}-0.35,0.32),-0.46 \quad(-1.12, \quad 0.02),-0.49 \quad(-1.52$, $0.54),-0.29(-0.72,0.14)$ and $-1.00(-1.83,-0.16) \mathrm{pg} /$ $\mathrm{mL}$, i.e., mean IL-6 was approximately $-1 \mathrm{pg} / \mathrm{mL}$ statistically significant difference between two groups at $96 \mathrm{~h}$. None of the co-variables could explain the heterogeneity. 
Table 6 Comparisons of IL between curcumin supplement and placebo

\begin{tabular}{|c|c|c|c|c|c|c|}
\hline \multirow[t]{2}{*}{ Author } & \multicolumn{3}{|c|}{ Curcumin } & \multicolumn{3}{|l|}{ Placebo } \\
\hline & $N$ & Mean & SD & $N$ & Mean & SD \\
\hline \multicolumn{7}{|l|}{ (a) IL preexercise } \\
\hline Nicol LM & 17 & 0 & 0 & 17 & 0 & 0 \\
\hline Tanabe Y & 14 & 0.85 & 0.14 & 14 & 0.7 & 0.14 \\
\hline McFarlin BK & 14 & 2.84 & 0.41 & 14 & 3.51 & 0.68 \\
\hline Tanabe Y scan pre & 10 & 2.66 & 0.41 & 10 & 2.33 & 0.25 \\
\hline Tanabe Y scan post & 10 & 2.58 & 0.41 & 10 & 2.62 & 0.66 \\
\hline Mallard AR (0-10) & 13 & 12.1 & 10.1 & 14 & 10.1 & 22 \\
\hline UMD (95\% Cl) & & & & $-0.03(-0.35 .0 .32)$ & & \\
\hline \multicolumn{7}{|l|}{ (b) IL at $24 \mathrm{~h}$} \\
\hline Nicol LM & 17 & 0 & 0 & 17 & 0.42 & 1.875 \\
\hline Tanabe Y & 14 & 0.77 & 0.21 & 14 & 1.13 & 0.56 \\
\hline McFarlin BK & 14 & 2.36 & 0.41 & 14 & 3.72 & 0.68 \\
\hline Tanabe Y scan pre & 10 & 2.7 & 0.5 & 10 & 3.11 & 0.99 \\
\hline Tanabe Y scan post & 10 & 2.99 & 0.33 & 10 & 2.7 & 0.86 \\
\hline Mallard AR (0-10) & 13 & 13.5 & 10.7 & 14 & 10.7 & 11.1 \\
\hline UMD (95\%Cl) & & & & $-0.46(-1.12,0.02)$ & & \\
\hline \multicolumn{7}{|l|}{ (c) IL at $48 \mathrm{~h}$} \\
\hline Nicol LM & 17 & 0.56 & 1.03 & 17 & 0 & 0 \\
\hline Tanabe Y & 14 & 0.92 & 0.28 & 14 & 0.92 & 0.42 \\
\hline McFarlin BK & 14 & 2.5 & 0.34 & 14 & 3.58 & 0.68 \\
\hline Mallard AR (0-10) & 13 & 14.4 & 12 & 14 & 12 & 11.6 \\
\hline UMD (95\%Cl) & & & & $-0.49(-1.52,0.54)$ & & \\
\hline \multicolumn{7}{|l|}{ (d) IL at $72 \mathrm{~h}$} \\
\hline Tanabe Y & 14 & 0.92 & 0.42 & 14 & 1.27 & 0.56 \\
\hline McFarlin BK & 14 & 2.64 & 0.41 & 14 & 3.45 & 0.68 \\
\hline Tanabe Y scan pre & 10 & 3.15 & 0.58 & 10 & 2.82 & 0.62 \\
\hline Tanabe Y scan post & 10 & 2.53 & 0.82 & 10 & 2.78 & 0.49 \\
\hline Mallard AR (0-10) & 13 & 12.2 & 11.6 & 14 & 11.7 & 10 \\
\hline UMD (95\%Cl) & & & & $-0.29(-0.72,0.14)$ & & \\
\hline \multicolumn{7}{|l|}{ (e) IL at $96 \mathrm{~h}$} \\
\hline Tanabe Y & 14 & 1.76 & 2.53 & 14 & 1.9 & 1.97 \\
\hline McFarlin BK & 14 & 2.3 & 0.41 & 14 & 3.51 & 0.68 \\
\hline UMD (95\%Cl) & & & & $-1.00(-1.83,-0.16)$ & & \\
\hline
\end{tabular}

Egger's test and a contour funnel plot did not suggest any evidence of publication bias.

\section{ROM at pre- and post-exercise, 24, 48, 72 and $96 \mathrm{~h}$}

The mean values of ROM between curcumin and placebo in post-exercise (eccentric elbow flexion) person at pre- and post-exercise, 24, 48, 72 and $96 \mathrm{~h}$ are shown in Table 7 and Fig. 6. The UMD was 1.18 (95\% CI - 1.30, $3.67),-0.30(-3.71,3.11), 2.30(-3.78,8.37), 4.57$ $(-4.85,14.00), 9.84(-0.02,19.70)$ and $8.45(-0.84$, 17.74) $\mathrm{pg} / \mathrm{mL}$, i.e., mean ROM had no statistically significant difference between two groups. Egger's test and a contour funnel plot did not suggest any evidence of publication bias.

\section{Discussion}

This review suggested that persons who took curcumin supplement before exercise have pain score of about 1 score lower than those who took placebo in and postexercise at 1, 2, 3 and 4 days. For indirect markers of muscle damage, the persons who took curcumin supplement before exercise have lower CK, TNF and IL score than those who took placebo. However, TNF and IL have no statistically significant difference between those two 


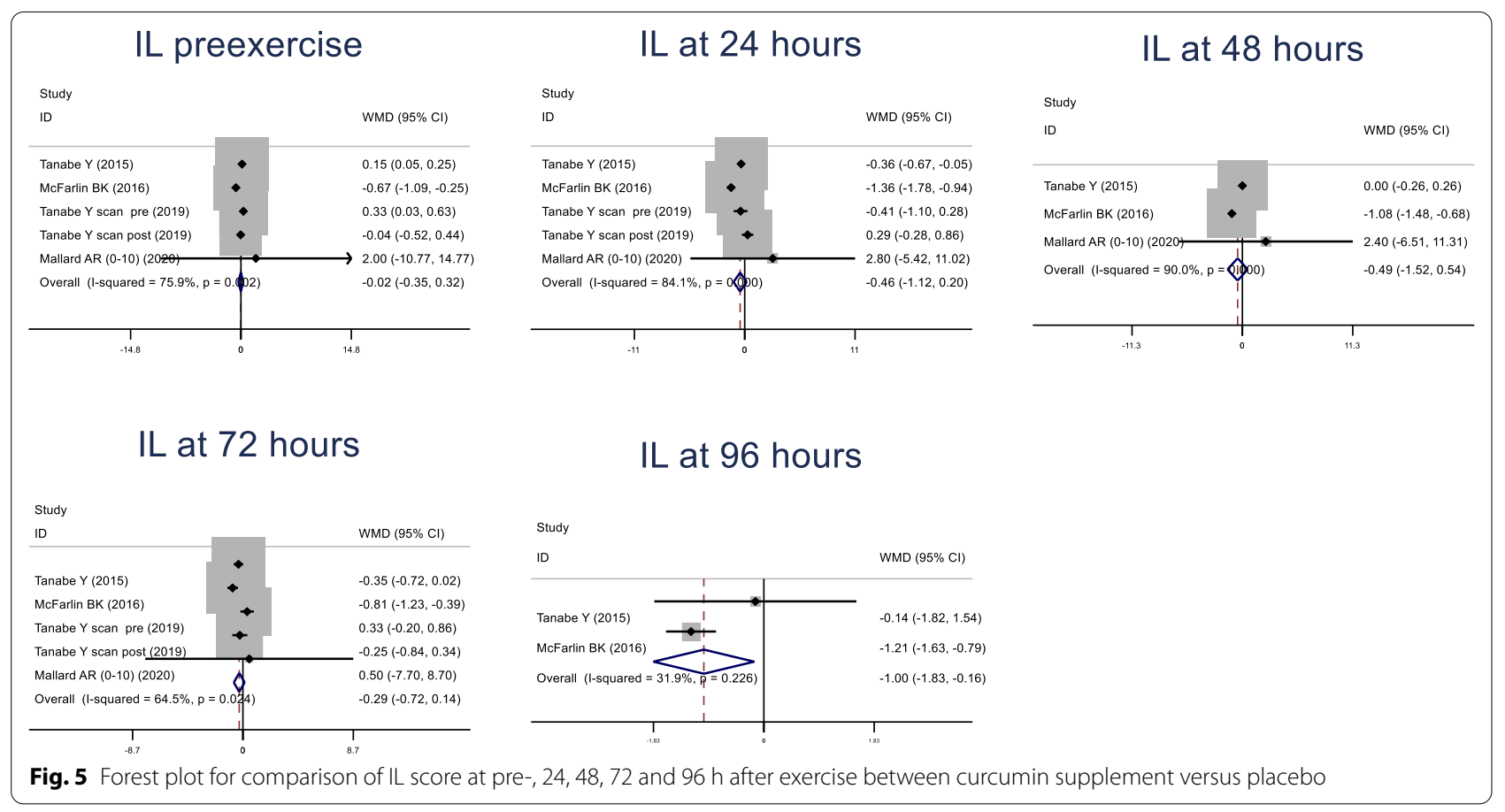

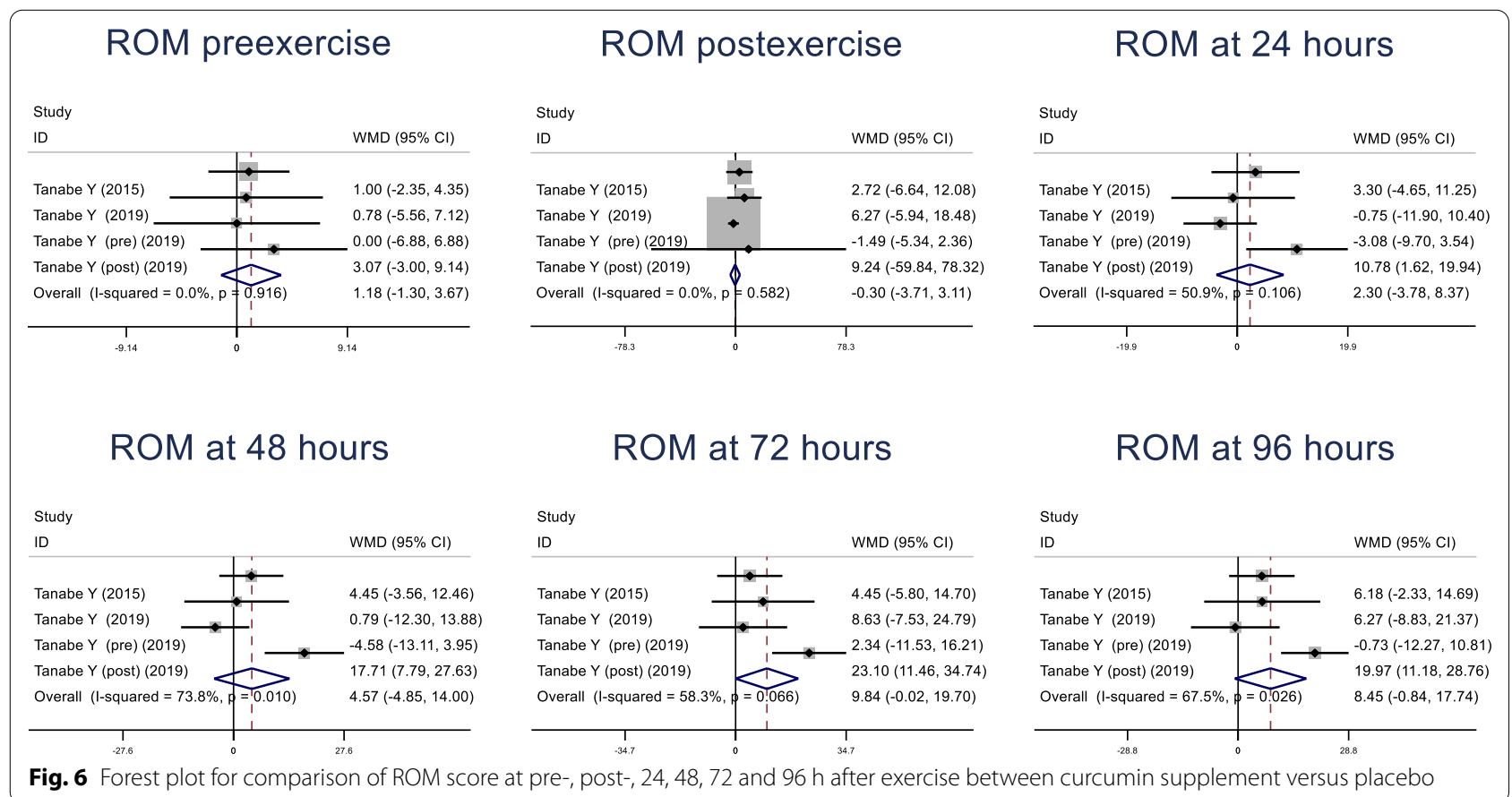

groups. In terms of ROM, no difference between the two groups in all follow-up time was shown. After all outcomes were pooled and the sources of heterogeneity were explored by meta-regression analysis, the differences of all co-variables were shown to have no effect on all outcomes.
From a review of previous meta-analysis (Fang and Nasir 2021), curcumin has efficacy in reducing CK serum levels and muscle soreness index among adults. Therefore, curcumin may be known as a priority EIMD recovery agent in interventions. However, previous metaanalyses have limitations as following: Included one study 
Table 7 Comparisons of ROM between curcumin supplement and placebo

\begin{tabular}{|c|c|c|c|c|c|c|}
\hline \multirow[t]{2}{*}{ Author } & \multicolumn{3}{|c|}{ Curcumin } & \multicolumn{3}{|l|}{ Placebo } \\
\hline & $N$ & Mean & SD & $N$ & Mean & SD \\
\hline \multicolumn{7}{|c|}{ (a) ROM preexercise } \\
\hline Tanabe Y & 14 & 134 & 4 & 14 & 133 & 5 \\
\hline Tanabe Y & 8 & 136.47 & 4.71 & 8 & 135.69 & 7.84 \\
\hline Tanabe Y (pre) & 10 & 133.85 & 9.24 & 10 & 133.85 & 6.16 \\
\hline Tanabe Y (post) & 10 & 136.92 & 6.93 & 10 & 133.85 & 6.93 \\
\hline UMD (95\% Cl) & & & & $1.18(-1.30,3.67)$ & & \\
\hline \multicolumn{7}{|c|}{ (b) ROM post-exercise } \\
\hline Tanabe Y & 14 & 115.03 & 12.64 & 14 & 112.31 & 12.64 \\
\hline Tanabe Y & 8 & 116.86 & 6.27 & 8 & 110.59 & 16.47 \\
\hline Tanabe Y (pre) & 10 & 116.2 & 5.39 & 10 & 117.69 & 3.08 \\
\hline Tanabe Y (post) & 10 & 119.28 & 110.77 & 10 & 110.04 & 12.32 \\
\hline UMD (95\% Cl) & & & & $-0.30(-3.71,3.11)$ & & \\
\hline \multicolumn{7}{|l|}{ (c) $R O M$ at $24 \mathrm{~h}$} \\
\hline Tanabe Y & 14 & 116.76 & 12.07 & 14 & 113.46 & 9.196 \\
\hline Tanabe Y & 8 & 112.98 & 10.98 & 8 & 113.73 & 11.76 \\
\hline Tanabe Y (pre) & 10 & 109.23 & 5.39 & 10 & 112.31 & 9.23 \\
\hline Tanabe Y (post) & 10 & 119.28 & 9.23 & 10 & 108.5 & 11.55 \\
\hline UMD (95\%Cl) & & & & $2.30(-3.78,8.37)$ & & \\
\hline \multicolumn{7}{|l|}{ (d) $\mathrm{ROM}$ at $48 \mathrm{~h}$} \\
\hline Tanabe Y & 14 & 118.48 & 12.64 & 14 & 114.03 & 8.62 \\
\hline Tanabe Y & 8 & 106.67 & 12.55 & 8 & 105.88 & 14.11 \\
\hline Tanabe Y (pre) & 10 & 103.11 & 6.16 & 10 & 107.69 & 12.31 \\
\hline Tanabe Y (post) & 10 & 118.51 & 9.23 & 10 & 100.8 & 13.08 \\
\hline UMD $(95 \% \mathrm{Cl})$ & & & & $\begin{array}{l}4.57(-4.85,14.00) \\
4.57(-4.85,14.00)\end{array}$ & & \\
\hline \multicolumn{7}{|l|}{ (e) $R O M$ at $72 \mathrm{~h}$} \\
\hline Tanabe Y & 14 & 119.06 & 12.64 & 14 & 114.61 & 14.94 \\
\hline Tanabe Y & 8 & 106.67 & 17.25 & 8 & 98.04 & 15.69 \\
\hline Tanabe Y (pre) & 10 & 106.19 & 16.94 & 10 & 103.85 & 14.62 \\
\hline Tanabe Y (post) & 10 & 120.05 & 10.77 & 10 & 96.95 & 15.38 \\
\hline UMD (95\%Cl) & & & & $9.84(-0.02,19.70)$ & & \\
\hline \multicolumn{7}{|l|}{ (f) $R O M$ at $96 \mathrm{~h}$} \\
\hline Tanabe Y & 14 & 122.51 & 11.49 & 14 & 116.33 & 11.49 \\
\hline Tanabe Y & 8 & 109.8 & 18.82 & 8 & 103.53 & 10.98 \\
\hline Tanabe Y (pre) & 10 & 110.04 & 9.24 & 10 & 110.77 & 16.16 \\
\hline Tanabe Y (post) & 10 & 123.85 & 9.23 & 10 & 103.88 & 10.77 \\
\hline UMD (95\%Cl) & & & & $8.45(-0.84,17.74)$ & & \\
\hline
\end{tabular}

(Delecroix et al. 2017) that reported a combination of curcumin and piperine, which is not equal to curcumin alone; did not explore the outcomes such as IL, TNF and ROM of curcumin when compared to placebo.

This study has several strengths. First of all, this study included 13 studies in the pooling of all important clinical outcomes of curcumin supplement and placebo. Secondly, we explore the possible causes of heterogeneity, when covariate data at baseline are available. Publication bias for each outcome was assessed. However, there are some limitations in this study. The scope of this study does not include other important outcomes such as adverse effects and cost-effective analysis, since there are incomplete data. Finally, only English publications were considered in this study. At present, more than one supplement is consumed before exercise to reduce pain after playing sports (EIMD or DOMS). This may be more effective than using one alone, but there is no comparative research yet. In the future, there should be more RCT studies to responding to playing sports effectively. 
Moreover, further RCT studies that assess combine effect of cost-effective analysis should be performed.

\section{Conclusion}

To conclude, curcumin supplement has reduced muscle soreness and CK after exercise after 1, 2, 3, and 4 days when compared to placebo. On the other hand, TNF and IL were not affected by curcumin ingestion. Further RCT studies that assess cost-effective analysis should be performed.

\begin{abstract}
Abbreviations
DOMS: Delayed-onset muscle soreness; ROS: Reactive oxygen species; NF-kB: Nuclear factor-KB; ROM: Range of motion; CK: Creatine kinase; IL: Interleukin; TNF: Tumor necrotic factor; COX: Cyclooxygenase; RCTs: Randomized controlled trial studies; VAS: Visual analog score; SD: Standard deviation; UMD: Unstandardized mean difference.
\end{abstract}

\section{Acknowledgements}

All authors declare no funding source or sponsor involvement in the study design, collection, analysis and interpretation of the data, in writing the manuscript, and in submission of the manuscript for publication.

\section{Authors' contributions}

NR was responsible for the conception and design research, collection data, analysis and interpretation results of the data, prepared figure, drafting manuscript. PP was responsible for the collection research data and assembly of data. JM was responsible for manuscript writing; JM edited and revised manuscript for important intellectual contents; and JM contributed to final approval of the article. KC was responsible for the collection research data and assembly of data. JK was responsible for the conception and design, and JK supervised in analysis and interpretation data, edited and revised manuscript, critical revision of the manuscript, approved final version of manuscript and statistical expertise. All authors have read and approved the final manuscript.

\section{Funding}

Not applicable.

\section{Availability of data and materials}

All data generated or analyzed during this study are included in this published article.

\section{Declarations}

Ethical approval and consent to participate

Not applicable.

\section{Consent for publication}

Not applicable.

\section{Competing of interests}

None.

\begin{abstract}
Author details
${ }^{1}$ St. Francis Xavier Convent School, Bangkok, Thailand. ${ }^{2}$ Faculty of Medicine Ramathibodi Hospital, Bangkok, Thailand. ${ }^{3}$ Sports Medicine Center, College of Sports Science and Technology, Mahidol University, Nakhon Pathom, Thailand. ${ }^{4}$ Department of Epidemiology and Biostatistics, Faculty of Medicine Ramathibodi Hospital, Bangkok, Thailand. ${ }^{5}$ Medpark Hospital, Bangkok, Thailand.
\end{abstract}

Received: 29 June 2021 Accepted: 13 November 2021

Published online: 27 November 2021

\section{References}

Aggarwal S, Ichikawa H, Takada Y, Sandur SK, Shishodia S, Aggarwal BB (2006) Curcumin (diferuloylmethane) down-regulates expression of cell proliferation and antiapoptotic and metastatic gene products through suppression of IkappaBalpha kinase and Akt activation. Mol Pharmacol 69(1):195-206. https://doi.org/10.1124/mol.105.017400

Amalraj A, Divya C, Gopi S (2020) The effects of bioavailable curcumin (Cureit) on delayed onset muscle soreness induced by eccentric continuous exercise: a randomized, placebo-controlled, double-blind clinical Study. J Med Food 23(5):545-553. https://doi.org/10.1089/jmf.2019.4533

Cardaci TD, Machek SB, Wilburn DT, Hwang PS, Willoughby DS (2020) Ubiquitin proteasome system activity is suppressed by curcumin following exercise-induced muscle damage in human skeletal muscle. J Am Coll Nutr. https://doi.org/10.1080/07315724.2020.1783721

Cheung K, Hume P, Maxwell L (2003) Delayed onset muscle soreness: treatment strategies and performance factors. Sports Medicine 33(2):145-164. https://doi.org/10.2165/00007256-200333020-00005

Cho JW, Lee KS, Kim CW (2007) Curcumin attenuates the expression of IL1 beta, IL-6, and TNF-alpha as well as cyclin E in TNF-alpha-treated HaCaT cells; NF-kappaB and MAPKs as potential upstream targets. Int J Mol Med 19(3):469-474

Chun KS, Keum YS, Han SS, Song YS, Kim SH, Surh YJ (2003) Curcumin inhibits phorbol ester-induced expression of cyclooxygenase-2 in mouse skin through suppression of extracellular signal-regulated kinase activity and NF-kappaB activation. Carcinogenesis 24(9):1515-1524. https://doi.org/ 10.1093/carcin/bgg107

Clarkson PM, Nosaka K, Braun B (1992) Muscle function after exerciseinduced muscle damage and rapid adaptation. Med Sci Sports Exerc 24(5):512-520

Delecroix B, Abaïdia AE, Leduc C, Dawson B, Dupont G (2017) Curcumin and piperine supplementation and recovery following exercise induced muscle damage: a randomized controlled trial. J Sports Sci Med 16(1):147-153

Drobnic F, Riera J, Appendino G, Togni S, Franceschi F, Valle X, Pons A, Tur J (2014) Reduction of delayed onset muscle soreness by a novel curcumin delivery system (Meriva ${ }^{\circledR}$ ): a randomised, placebo-controlled trial. J Int Soc Sports Nutr. https://doi.org/10.1186/1550-2783-11-31

Duval S, Tweedie R (2000) Trim and fill: a simple funnel-plot-based method of testing and adjusting for publication bias in meta-analysis. Biometrics 56(2):455-463

Egger M, Davey Smith G, Schneider M, Minder C (1997) Bias in meta-analysis detected by a simple, graphical test. BMJ 315(7109):629-634

Fang W, Nasir Y (2021) The effect of curcumin supplementation on recovery following exercise-induced muscle damage and delayed-onset muscle soreness: a systematic review and meta-analysis of randomized controlled trials. Phytother Res 35(4):1768-1781. https://doi.org/10.1002/ ptr.6912

García-López D, Cuevas MJ, Almar M, Lima E, De Paz JA, González-Gallego J (2007) Effects of eccentric exercise on NF-kappaB activation in blood mononuclear cells. Med Sci Sports Exerc 39(4):653-664. https://doi.org/ 10.1249/mss.0b013e31802f04f6

Hatcher H, Planalp R, Cho J, Torti FM, Torti SV (2008) Curcumin: from ancient medicine to current clinical trials. Cell Mol Life Sci 65(11):1631-1652. https://doi.org/10.1007/s00018-008-7452-4

Hillman AR, Gerchman A, O'Hora E (2021) Ten days of curcumin supplementation attenuates subjective soreness and maintains muscular power following plyometric exercise. J Diet Suppl. https://doi.org/10.1080/19390 211.2021.1875101

Howatson G, van Someren KA (2008) The prevention and treatment of exercise-induced muscle damage. Sports Med 38(6):483-503. https://doi. org/10.2165/00007256-200838060-00004

Jäger R, Purpura M, Kerksick CM (2019) Eight weeks of a high dose of curcumin supplementation may attenuate performance decrements following muscle-damaging exercise. Nutrients. https://doi.org/10.3390/nu110 71692

Kim J, So WY (2019) Effects of acute grape seed extract supplementation on muscle damage after eccentric exercise: a randomized, controlled clinical trial. J Exerc Sci Fit 17(2):77-79. https://doi.org/10.1016/j.jesf.2019.01.001

Lewis PB, Ruby D, Bush-Joseph CA (2012) Muscle soreness and delayed-onset muscle soreness. Clin Sports Med 31(2):255-262. https://doi.org/10. 1016/j.csm.2011.09.009 
Liberati A, Altman DG, Tetzlaff J, Mulrow C, Gotzsche PC, loannidis JP, Clarke M, Devereaux PJ, Kleijnen J, Moher D (2009) The PRISMA statement for reporting systematic reviews and meta-analyses of studies that evaluate health care interventions: explanation and elaboration. PLoS Med 6(7):1000-100

Mallard AR, Briskey D (2020) Curcumin improves delayed onset muscle soreness and postexercise lactate accumulation. J Diet Suppl 66:1-12. https:// doi.org/10.1080/19390211.2020.1796885

McFarlin BK, Venable AS, Henning AL, Sampson JN, Pennel K, Vingren JL, Hill DW (2016) Reduced inflammatory and muscle damage biomarkers following oral supplementation with bioavailable curcumin. BBA Clin 5:72-78. https://doi.org/10.1016/j.bbacli.2016.02.003

Mizumura K, Taguchi T (2016) Delayed onset muscle soreness: involvement of neurotrophic factors. J Physiol Sci 66(1):43-52. https://doi.org/10.1007/ s12576-015-0397-0

Ms SAB, Waldman Ph DH, Krings Ph DB, Lamberth Ph DJ, Smith Ph DJ, McAllister Ph DM (2020) Effect of curcumin supplementation on exerciseinduced oxidative stress. Inflamm Muscle Damage Muscle Soren 17(4):401-414. https://doi.org/10.1080/19390211.2019.1604604

Nakhostin-Roohi B, Nasirvand Moradlou A, Mahmoodi Hamidabad S, Ghanivand $B$ (2016) The effect of curcumin supplementation on selected markers of delayed onset muscle soreness (DOMS). Ann Appl Sport Sci 4(2):25-31

Nicol LM, Rowlands DS, Fazakerly R, Kellett J (2015) Curcumin supplementation likely attenuates delayed onset muscle soreness (DOMS). Eur J Appl Physiol 115(8):1769-1777. https://doi.org/10.1007/s00421-015-3152-6

Ota H, Katanosaka K, Murase S, Kashio M, Tominaga M, Mizumura K (2013) TRPV1 and TRPV4 play pivotal roles in delayed onset muscle soreness. PLoS ONE 8(6):e65751. https://doi.org/10.1371/journal.pone.0065751

Palmer TM, Peter JL, Sutton AJ, Moreno SG (2020) Contour-enhanced funnel plots for meta-analysis. STATA J 8(2):242-254

Smith LL (1991) Acute inflammation: the underlying mechanism in delayed onset muscle soreness? Med Sci Sports Exerc 23(5):542-55

StataCorp (2017) Stata statistical software: release 15. StataCorp LLC, College Station

Takahashi H, Kuno S, Miyamoto T, Yoshioka H, Inaki M, Akima H, Katsuta S, Anno I, Itai $Y$ (1994) Changes in magnetic resonance images in human skeletal muscle after eccentric exercise. Eur J Appl Physiol 69(5):408-413. https://doi.org/10.1007/bf00865404

Tanabe Y, Maeda S, Akazawa N, Zempo-Miyaki A, Choi Y, Ra SG, Imaizumi A, Otsuka Y, Nosaka K (2015) Attenuation of indirect markers of eccentric exercise-induced muscle damage by curcumin. Eur J Appl Physiol 115(9):1949-1957. https://doi.org/10.1007/s00421-015-3170-4

Tanabe Y, Chino K, Ohnishi T, Ozawa H, Sagayama H, Maeda S, Takahashi H (2019) Effects of oral curcumin ingested before or after eccentric exercise on markers of muscle damage and inflammation. Scand J Med Sci Sports 29(4):524-534. https://doi.org/10.1111/sms.13373

Thapa A, Vernon BC, De la Peña K, Soliz G, Moreno HA, López GP, Chi EY (2013) Membrane-mediated neuroprotection by curcumin from amyloid- $\beta$ peptide-induced toxicity. Langmuir 29(37):11713-11723. https://doi.org/ 10.1021/la4020459

Tiidus PM (1998) Radical species in inflammation and overtraining. Can J Physiol Pharmacol 76(5):533-538. https://doi.org/10.1139/cjpp-76-5-533

Urai H, Murase S, Mizumura K (2013) Decreased nerve growth factor upregulation is a mechanism for reduced mechanical hyperalgesia after the second bout of exercise in rats. Scand J Med Sci Sports 23(2):e96-101. https://doi.org/10.1111/sms.12013

Warren GL, Lowe DA, Armstrong RB (1999) Measurement tools used in the study of eccentric contraction-induced injury. Sports Med 27(1):43-59. https://doi.org/10.2165/00007256-199927010-00004

Yoon WY, Lee K, Kim J (2020) Curcumin supplementation and delayed onset muscle soreness (DOMS): effects, mechanisms, and practical considerations. Phys Activity Nutr 24(3):39-43. https://doi.org/10.20463/pan.2020 0020

\section{Publisher's Note}

Springer Nature remains neutral with regard to jurisdictional claims in published maps and institutional affiliations.

\section{Submit your manuscript to a SpringerOpen ${ }^{\odot}$ journal and benefit from:}

- Convenient online submission

- Rigorous peer review

- Open access: articles freely available online

- High visibility within the field

- Retaining the copyright to your article

Submit your next manuscript at $\boldsymbol{\nabla}$ springeropen.com 